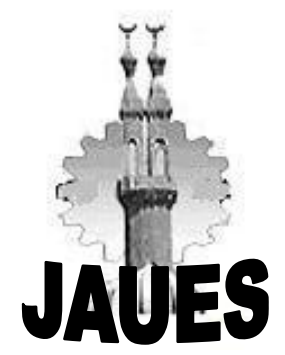

Journal Of Al Azhar University Engineering Sector

Vol. 12, No. 44, July, 2017, 900-906

\title{
MEASURING URBAN QUALITY OF LIFE: CASE STUDY OF MADINET NASR
}

\author{
Moataz Mohamed, Yasser Mansour, Mohamed gabr and Ayman Assem \\ Ain Shams Univeristy, Department of architecture, Cairo, Egypt
}

\begin{abstract}
Madinet Nasr is by far the most attractive area for residents to live in Cairo; it was the first planned area after Cairo master plan execution in 1956. Although the district follows the invasion and relay rule, but it has rapid population growth; which affect its physical setting, urban and social aspects. These sides could be tracked from residents' responds. The study aims to measure and analyze quality of urban life (QOUL) and quality of life (QOL) as they related to each other; using subjective test and structure equation modeling, results show that QOUL and QOL did not affect by population growth or urban horizontal and vertical expansion. The research came atthe conclusion that high appeal areas (attractive areas) have a positive effect on QOUL and QOL.
\end{abstract}

\section{KEY WORDS: QOL, Quality of life, QOUL, Quality of urban life, Madinet Nasr}

\section{INTRODUCTION}

Quality of urban life (QOUL) has become popular idea since the communities' populations have been increased in a worldwide lately, the measurements are important to evaluate a community or compare different communities. QOUL as a tool helps policy makers and urban planners to solve community problems through evaluating community needs and problems. QOUL concept is directly related to other terms like livability, well-being, satisfaction and happiness. The concept of QOL went through three stages in the past 90 years, first it's mainly focused on social indicators then it developed to include the urban amenity, and at last it spreads to include the environmental concerns. Through these stages the term Quality of urban life (QOUL) was evolved and defined as the QOL as it related to place, particularly in different urban spaces. Research first present a brief overview on study area after it set an urban limits and a methodology to how data and measures had been collected and done. Finally, the research discusses the measure findings and analyzes the results.

\section{BRIEF ABOUT MADINET NASR}

Madinet Nasr was established by Gamal Abdel Nasser presidential decree no. 815 (1959), MDHD (Madinet Nasr Company for Housing and Reconstruction) was established to urbanize the new area. The selected site located to the southern east of an empty desert (except for a mental hospital, and the old British barracks inherited by the Egyptian army). This site is bordered by Heliopolis from the north and Abbasiya from the west. The district was built to be the new extension for Cairo for two goals; to solve the housing problem in Cairo, and to celebrate 1957 victories on Tripartite Aggression. It was planned to be "city within a city" with complete services and different land uses as residential, commercial, industrial, recreational, educational, and governmental uses, spread on 80.94 kilometer square. Architect and planner Sayed Karim had done the most of Madinet Nasr urban master plan and architectural designs. The design was created per the latest theories of city planning (orthogonal plan composed of "super blocks" each containing housing block) which 


\section{MEASURING URBAN QUALITY OF LIFE: CASE STUDY OF MADINET NASR}

were directed to educated upper and middle-class residents. He planned a series of new administrative buildings to build new ministries and to relocate others from the downtown area. Nowadays, Madinet Nasr is considered as one of the most attractive areas for living in Cairo, this was enough to raise land value to more than twice its real value also increased population from 200,000 people as planned to 750,000 people and keep going, the district still expanding horizontally by MDHD and vertically by users.

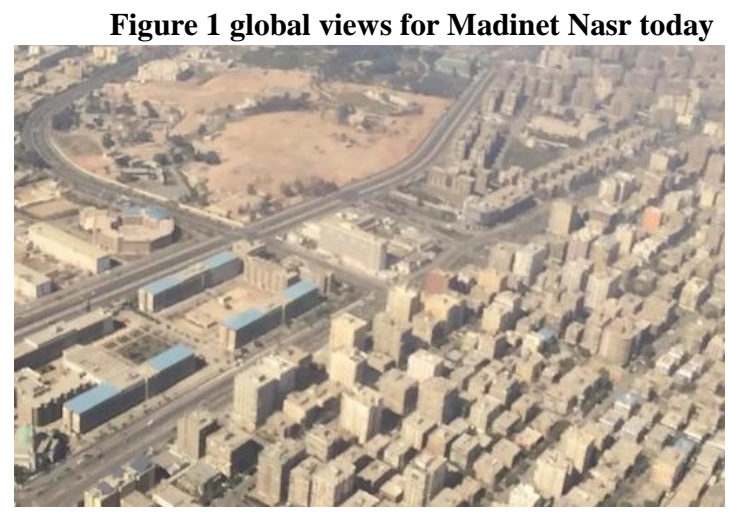

Figure 2 vertical expansion in Madinet Nasr today

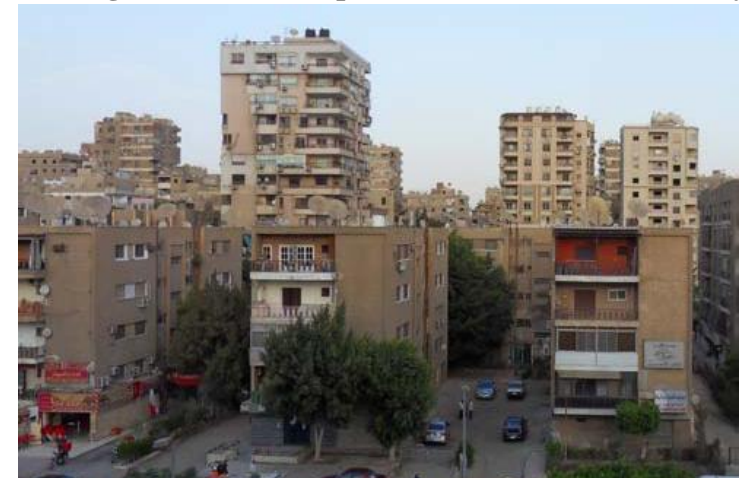

\section{RESEARCH URBAN LIMITS}

\section{*Google maps}

Madinet Nasr has 25 governmental areas (Shyakha) in two main administrations "east Madinet Nasr and west Madinet Nasr" with different characteristics and land uses. The area of study was chosen based on two main conditions:

a. Residential areas continuity (residential zones in some areas are far from others) problems may differ from area to other especially far areas.

b. Regulated areas (some areas are illegally built) illegal areas already have more needs than regulated areas that widen the spectrum of the study.

Figure 3 Selected areas from Madinet Nasr

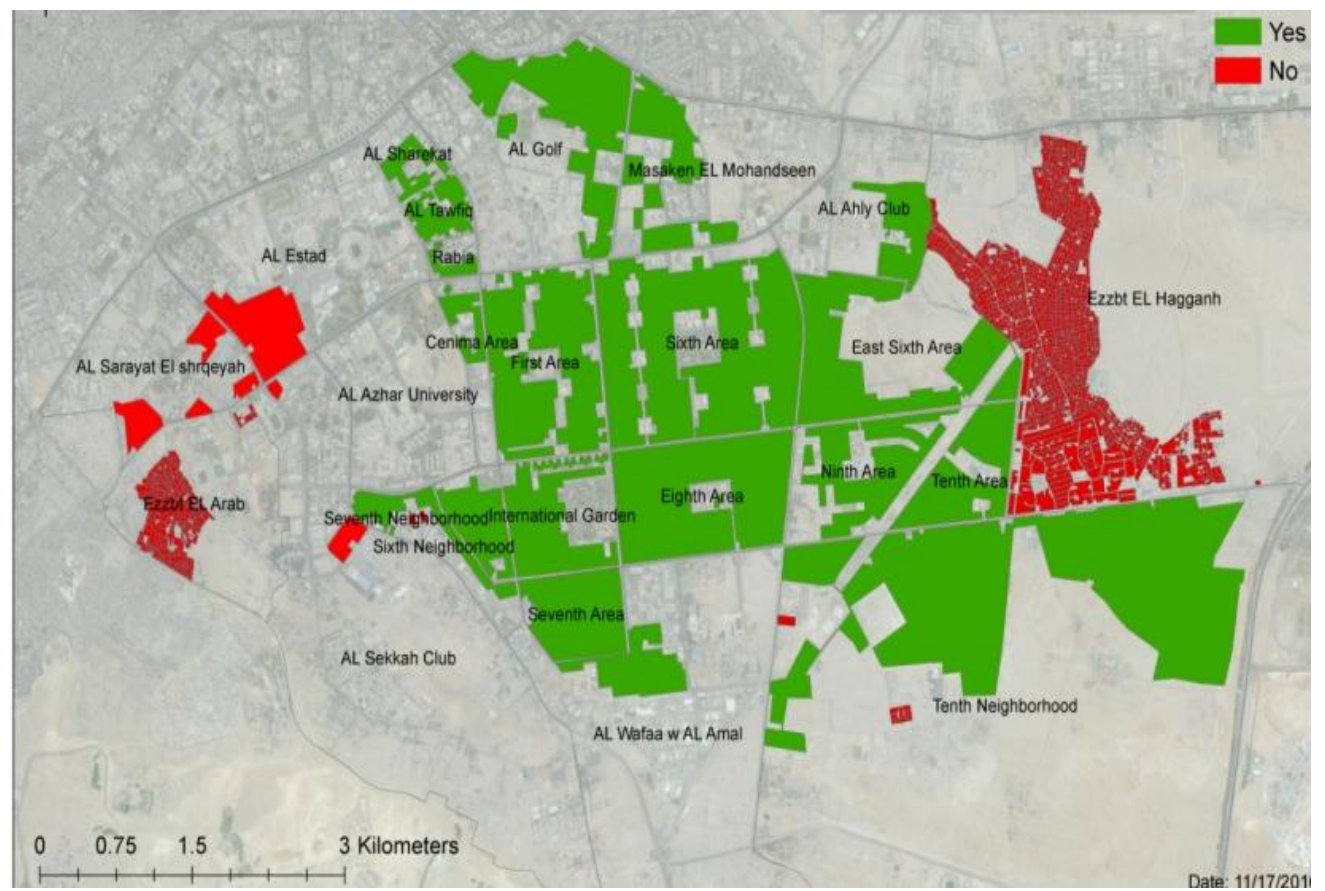




\title{
MEASURING URBAN QUALITY OF LIFE: CASE STUDY OF MADINET NASR
}

\author{
*By Authors
}

After applying the selected two conditions only 19 areas were selected from the total 25 areas Figure 3 , two areas were illegally built and three areas were not connected and one has no residential area.

\section{RESEARCH METHODOLOGY}

QOUL was measured also through subjective quality of life (SQL) using bottom up model were the satisfaction in sub-domains like safety; services, neighbors and friendliness predict the satisfaction in urban domains like neighborhood and community; through three level of analysis (dwelling, neighborhood, district) as the term QOUL have different levels Campbell, Converse et al. (1976).Many of studies used this approach Marans and Rodgers (1975), McCrea, Stimson et al. (2005) and Sirgy and Cornwell (2001).

\subsection{Selecting Needs}

QOL measurement depends on people needs; it changes already from place to another as Mazumdar (2003) confirmed that QOL domains priorities and importance changes from country to another, due to cultural and religious different habits. Research designed a focus group study to select and arrange human needs priorities for the study area; the human needs was based on Lang (1994)framework which built on Maslow's theory. The framework aims to connect human needs with physical environment. Lang framework divides human needs in two main categories basic needs and higher level needs, which branches into six sub categories resulting twenty eight needs.

A focus group of 30 volunteers was randomly selected from different regions in study area; the study main goals were explained to them for 30 minutes. Then each volunteer was asked to rank the human needs from his point of view according to their importance. Questions were translated into Arabic, and each question has three choices "very important," "important" and "not important." Furthermore, the group was asked if they have a clear understanding to the needs' meaning. Avoid any misunderstanding during the session. Then volunteers were asked to explain some results of their choices.

\subsection{Questionnaire Design}

Research questionnaire structure based on DAS (Detroit Area Study by University of Michigan) questionnaire structure as a reference, it was modified to meet up the selected needs from the focus group results, and the structure expanded to include objective, behavioral, subjective variables to enrich study validity.

According to andrews and Withy (1976) people divide their lives into related domains, also people can judge each domain individually, researchers confirmed that most of QOL researches are concerned with the relation between domains and whole QOL, some researchers examined the relation between QOL and single domain like financial domain Bilshen and Atkinson (1980), neighborhood satisfaction Gutek, Allen et al. (1983).

Each domain consists of group of questions testing selected needs through three types of variables, and testing as well the three levels of QOUL.As confirmed by Campbell, Converse et al. (1976).

\subsection{Question Formatting}

Questions were designed to be closed-end, multi-choose answers or on-off questions. Using Campbell (1976)Proposed questions like - How satisfied are you with your life as a whole these days? - And the answer was a likert scale from 1 to 7. Questions were written in Arabic language.

\subsection{Research Sample}

The total population of study area estimated in (2016) 588,384 persons using annual growth rate 2.45\%(according to Central Agency for Public Mobilization and Statistics), sample size value was 382 samples with Sampling fraction is 0.000649and distributed as in Figure 4.

Total sample size was determined by Krejcie and Morgan (1970) table after calculating the population of selected areas. Research used a sampling approach based on Proportionate Stratified 


\section{MEASURING URBAN QUALITY OF LIFE: CASE STUDY OF MADINET NASR}

Random Sampling which depends on fixed sampling fraction for different neighborhoods population.

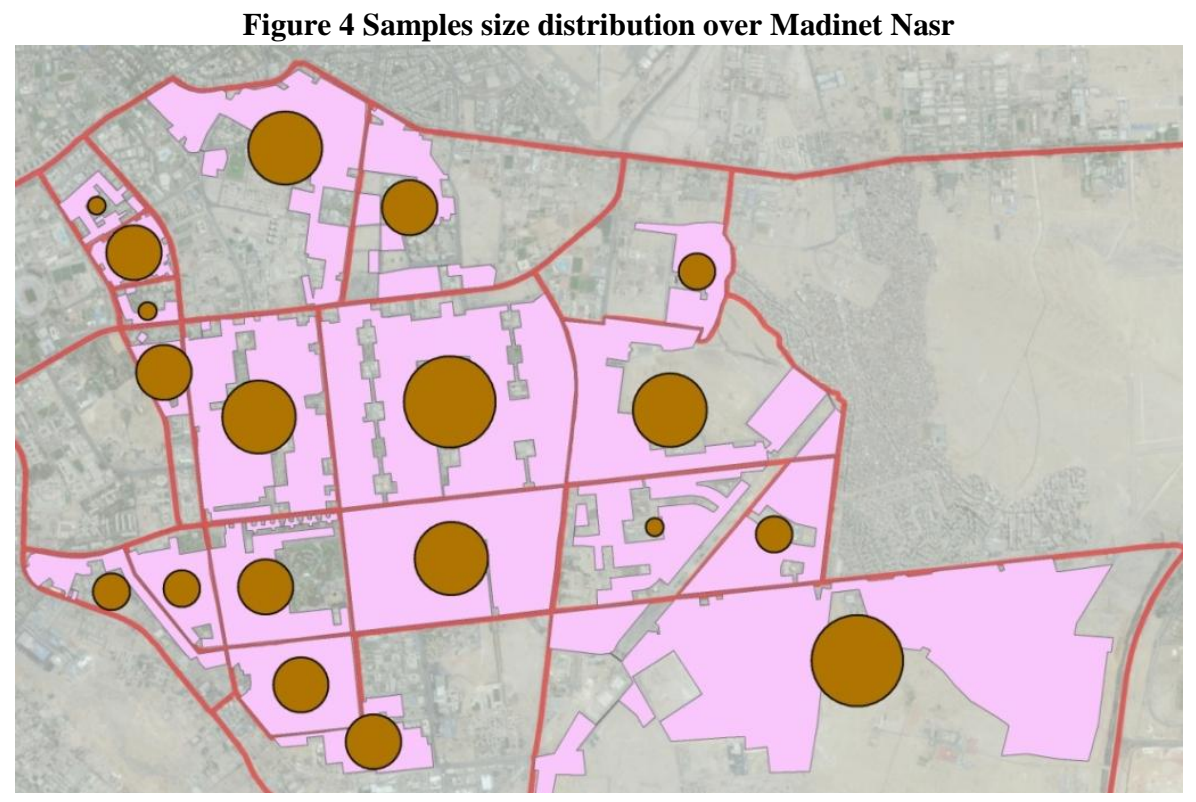

\subsection{Data Collection}

\section{*By Authors}

Almost all data were collected through direct interviews by the researchers and their well-trained assistants, only small amount 5\% of data were collected through online internet form. Data were analyzed using IBM SPSS software and simulation done by its extension AMOS.

\section{RESEARCH FINDINGS}

\subsection{Overall quality of life (QOL) in Madinet Nasr}

The respondents were asked to assess main QOL domains using 7 points likert scale ranging from

(1) completely not satisfied to (7) completely satisfied.

Table 1 respondent's scores mean values for quality of life domains

\begin{tabular}{lll}
\hline Domain & Mean Score & Standard Deviation \\
\hline Family Life & 3.64 & 1.2 \\
Friends & 4.33 & 1.4 \\
Health & 4.77 & 1.7 \\
JoblSchool & 4.387 & 1.6 \\
Time to Work & 4.77 & 1.7 \\
Spare time & 3.68 & 1.4 \\
Safety & 3.71 & 1.8
\end{tabular}

*By Authors

Table 1 shows the mean scores for QOL domains, satisfaction scores for family, spare time and safety are approximately (4) equivocal (below 4). This means them barely equivocal with these domains; for example respondents were asked if they saw crimes occurred in their areas lately and about their feelings about crime rate, only50\% saw few crimes, $29 \%$ saw some of crimes and $21 \%$ 


\section{MEASURING URBAN QUALITY OF LIFE: CASE STUDY OF MADINET NASR}

saw a lot crimes, $40 \%$ felt increasing in crime rate, $41 \%$ felt that crime rate as it is and $19 \%$ felt that crime rate decreased. Figure 5, 6

Figure 5 Crimes Occurred in your area lately

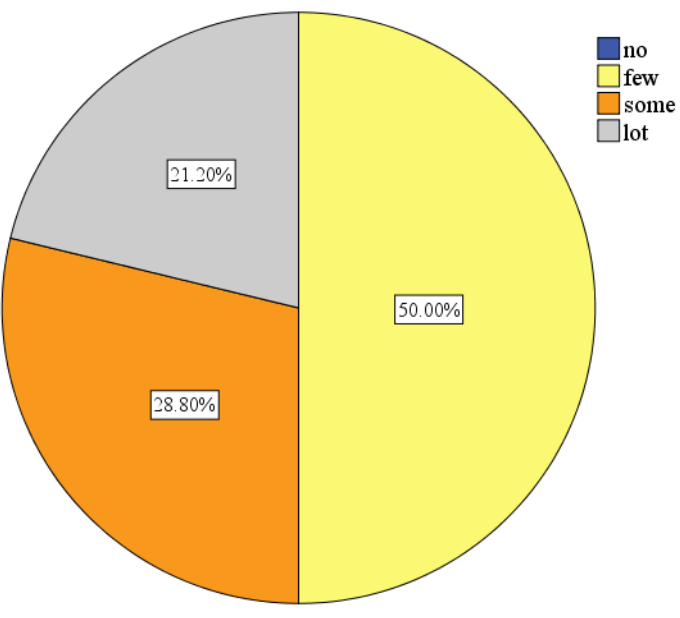

*By Authors
Figure 6 Feeling about crime rate lately

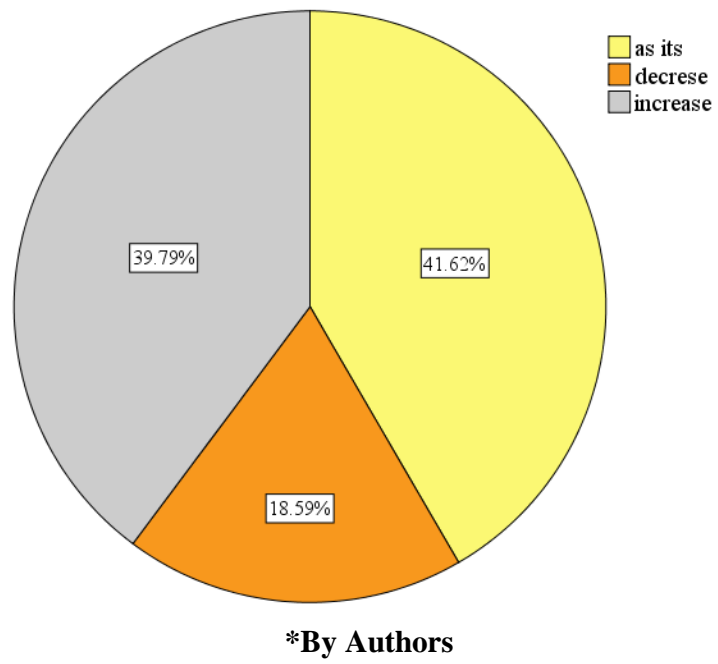

Also family satisfaction for example they were asked about family spending priorities and how much they spend per day, $51 \%$ said education is their first priority, $36.5 \%$ said health is their first priority, $11.5 \%$ said house is their first priority and only $1 \%$ said food is their first priority.

$61 \%$ spend from 100-200LE daily, 29\% spend from 50-100LE daily, 9\% spend from 10-50LE daily and only $1 \%$ spend from 200-500LE daily. Figure 7, 8

Figure 7 Family spending priorities

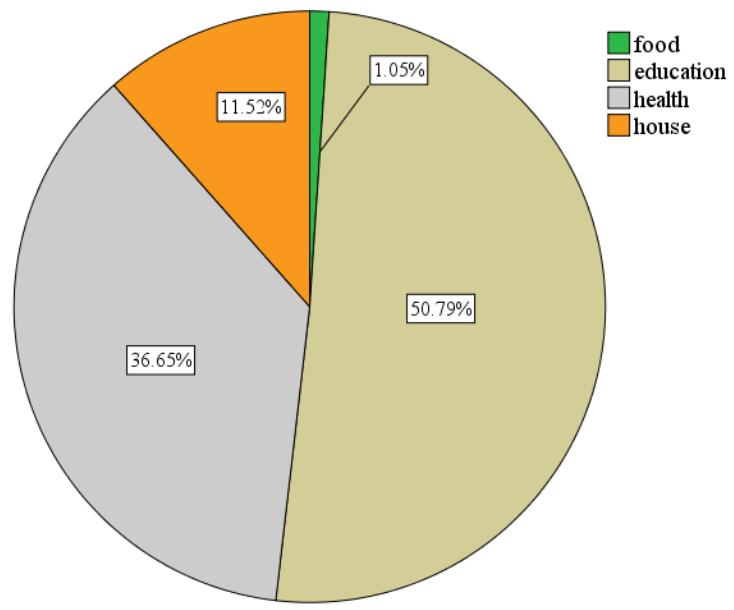

*By Authors
Figure 8Family spending per day

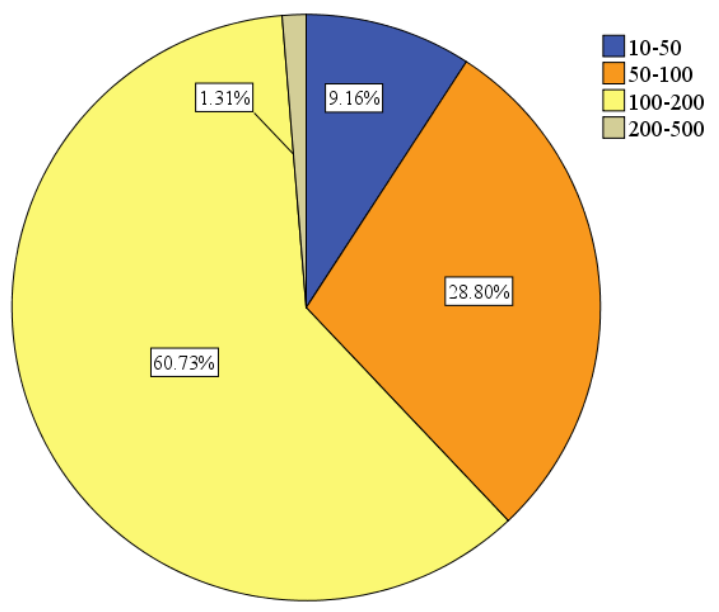

*By Authors

Table 1 shows satisfaction scores for friends and job or school which is almost (4) equivocal, the satisfaction with friends domain were tested for example with the ability to create new friends from neighbors or have already nearby living friends, 70\% did not know their neighbors names and $49 \%$ have living nearby friends.

Job satisfaction tested for example with the availability of jobs in your neighborhood, $42 \%$ of respondents few jobs, $27 \%$ plenty jobs and $31 \%$ available jobs in their area.School satisfaction also was tested directly through how they feel about school and education process. 


\section{MEASURING URBAN QUALITY OF LIFE: CASE STUDY OF MADINET NASR}

Table 1 also shows health and Time to work satisfaction which values approximately (5) somewhat satisfied, health satisfaction domain tested for example by visiting health facilities in the last year which was $85 \%$ and only $15 \%$ did not visit the health facility last year.

Time to work domain tested directly if their currently job satisfying in time and money and you do not need another job.

\subsection{Quality of urban life (QOUL) in Madinet Nasr}

Madinet Nasr as urban environment was divided into three levels analysis dwelling (street you live in), neighborhood (shyakha), and district (Madinet Nasr).

Respondents were asked to evaluate several attributes for each level and then give a summary satisfaction score to a single question using likert 7 points scale ranging from (1) completely not satisfied to (7) completely satisfied.

Table 2 QOUL levels respondents mean scores

\begin{tabular}{lll} 
Domain & Mean Score & Standard Deviation \\
\hline Dwelling Satisfaction & 4.72 & 1.6 \\
Neighborhood Satisfaction & 4.13 & 2 \\
District Satisfaction & 5.56 & 1.3
\end{tabular}

*By Authors

Table 2 presents mean satisfaction scores for different urban levels; the mean scores for all levels are comparable; the lowest value was for neighborhood level which was above (4) equivocal; the highest value was for district level above (5)somewhat satisfied and goes for (6) satisfied.

Research studies the relation between QOUL levels and QOL domains through path diagram simulation using structure equation modeling.

The model consists of two variables groups one for QOUL and other for QOL domains connected through QOL as a latent variable (to be estimated).

Figure 9 Structure equation modeling demonstrate relation between QOUL and QOL

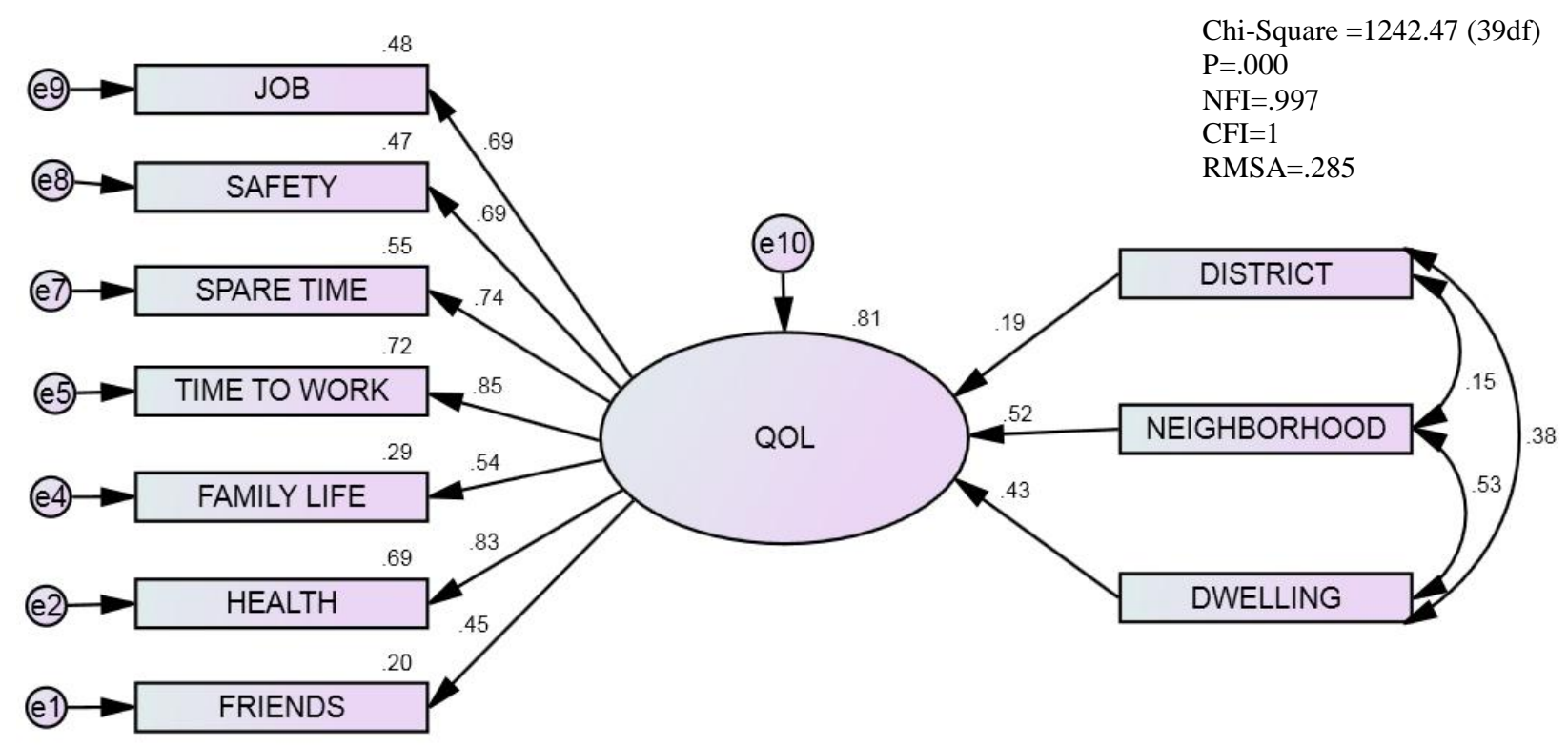

*By Author

QOUL three levels were connected exogeneous variables and QOL domains were connected as endogeneous variables. 


\section{MEASURING URBAN QUALITY OF LIFE: CASE STUDY OF MADINET NASR}

Figure 6 shows that the three place domains account for about $81 \%$ of the variance in the QOL, neighborhood level was the strongest predictor for QOL also dwelling level was the second highest predictor for QOL and the district level was the lowest value for predicting QOL.

\section{CONCLUSION}

Respondents have many issues in QOL domains like safety; although 20\% saw crimes lately in their areas but $40 \%$ feel that crime rate increasing this feeling raise users desire to move and lowering the price of the area this helps new user to come over with new characteristics to deal with safety problems. (This happened only in the areas with low safety feeling not all over study area).

Also appears in family spending priorities that health and education are very important and not balanced with other spending fields, this means there are problem in public health service and public education service which push users directly to search for more efficient services in private sectors with high prices.

Although Madinet Nasr has many problems so far, but it still attractive to many resident, results show they see that Madinet Nasr is better than other area in Cairo.

This appears in their response to QOL domains satisfaction, almost all values tend to (4) equivocal that's mean life in Madinet Nasr not bad also not good; its balanced as much problem they find they also find some benefits remedy these problems back.

Although they respond that many problems like crime, drugs, lack of some services, lack of green areas and social problems, but residents also responded to QOUL in high values tend to (5) somewhat satisfied, this explain the high satisfaction values of QOL.

Research were conducted through first part of year 2015, and it is really recommended to be applied again to observe the change in resident's satisfaction cause the area still expanding, and population growth at the same time increases.

\section{REFERENCES}

1. andrews, F. M. and S. B. Withy (1976). Social Indicators of well being: the development and measurment of perceptual indicators. New York, Plenum.

2. Bilshen, B. and T. Atkinson, Eds. (1980). Anglophone and francophone differences in perceptions of the quality of life in canada. The Quality of life:Comparative Studies. Londone, Sege Publications.

3. Campbell, A. (1976). "Subjective Measures of well-being." American pschologist31: 117-124.

4. Campbell, A., P. Converse, et al. (1976). The Quality of American Life: perceptions, evaluations and satisfactions New York, Russel Sage Foundation.

5. Gutek, B. A., H. Allen, et al. (1983). "The importance of internal referents as determinants of satisfaction." Journal of Community Psychology11: 111-120.

6. Krejcie, R. V. and D. W. Morgan (1970). "Determining sample size for research activities." Educational and psychological measurement.30: 607-610.

7. Lang, j. (1994). Urban design: The American Experience. New York, Van Nostrand Reinhold.

8. Marans, R. W. and W. Rodgers (1975). Toward an understanding of commuinty satisfaction Metropolitan America in Contemporary Perspective. V. Rock and A. Hawley. New York, Halsted: 299-352.

9. Mazumdar, S. (2003). Sense of Place Considerations for Quality of Urban Life. 1st International Conference on Quality of Urban Life: Policy Versus Practice. N. Z. Gulersoy, N. Esin and A. Ozsoy. Istanbul Technical University, Urban and Environmental Planning Research Center 8397.

10. McCrea, R., R. Stimson, et al. (2005). "Testing a moderated model of satisfaction with urban living using data for Brisbane-South east Queensland." Soc. Indic. Res. 72: 121-152. 


\section{MEASURING URBAN QUALITY OF LIFE: CASE STUDY OF MADINET NASR}

11. Sirgy, M. J. and T. Cornwell (2001). "Further validation of the Sirgy et al.'s mesure of commuinty quality of life." Social Indicators Research56(2): 125-143. 